\title{
An Extract of Young Olive Fruit Residues Attenuates Oxidative Stress in HaCaT Keratinocytes through the Ativation of Nrf2 Signaling
}

\author{
Madoka Yoshikawa, Taeko Mizutani, Yuri Okano, and Hitoshi Masaki* \\ Tokyo University of Technology, 1404-1 Katakura-machi, Hachioji-shi, 192-0982 Tokyo, JAPAN
}

\begin{abstract}
Residues of olive fruit (ROF) after the extraction of oils are an increasing source of industrial waste, because olive oil is becoming more popular as a healthy food. It has been reported that olives have some polyphenols that have an antioxidation capability. On the other hand, excess oxidative stress disrupts epidermal barrier function. This study was conducted to determine whether ROF could be utilized as an antioxidant source to reduce industrial wastes and to identify possible active materials to maintain healthy skin. Olive fruits are categorized into two groups depending on the time of harvest, young fruit (YF) and mature fruit (MF). Thus, we examined the antioxidant potentials of extracts from YF and from MF to remove reactive oxygen species (ROS) from biological and chemical aspects. HaCaT keratinocytes cultured with extracts of YF or MF had reduced levels of intracellular ROS in spite of the relatively low chemical capability against ROS scavenging. The biological effects of the YF extract were superior to those of the MF extract. The YF extract showed effective reductions of intracellular ROS and carbonylated proteins that were elevated by the stress-related hormone cortisol. In addition, the YF extract reinforced the intracellular antioxidation capability through the activation of Nrf2 signaling. Taken together, the YF extract was an effective source to reinforce the intracellular antioxidation capability. We conclude from these results that utilizing ROF would lead to the reduction of industrial wastes and would supply active materials to maintain healthy skin.
\end{abstract}

Key words: olive, $\mathrm{H}_{2} \mathrm{O}_{2}$, cortisol, $\mathrm{Nrf2}$

\section{Introduction}

Because the skin is the outermost layer of the body, it plays a critical defensive role against environmental stimuli from physical and chemical aspects ${ }^{1)}$. In general, most environmental stimuli work in the skin as generators of reactive oxygen species (ROS). For example, ultraviolet light (UV) generates superoxide anion radicals $\left(\cdot \mathrm{O}_{2}{ }^{-}\right)$through the activation of NADPH oxidase ${ }^{2,3)}$. In addition, our recent study has shown that sodium lauryl sulfate also stimulates the generation of $\cdot \mathrm{O}_{2}{ }^{-}$in HaCaT keratinocytes ${ }^{4)}$. Furthermore, air pollutants, which have adverse influences on human health, increase levels of intracellular $\operatorname{ROS}^{5}$ through the activation of aryl hydrocarbon receptors ${ }^{6)}$. Indeed, some epidemiological studies have demonstrated that subjects who live in air-polluted areas develop wrinkles and pigmented spots in their skin at a higher frequency compared with those who live in non-air-polluted areas ${ }^{7)}$.

Meanwhile, rapid changes in social environments cause additional mental stress for human beings. In general, mental stress is estimated by measuring the level of cortisol in the saliva ${ }^{8)}$. A recent study reported that cortisol stimulates the generation of ROS through glucocorticoid receptors ${ }^{9)}$. The sum of those facts strongly indicates that the skin is always exposed to higher oxidative stress induced not only from the outer environment but also from inner mental stress.

The influence of oxidative stress on skin conditions has been actively investigated by many research groups. Those results have shown that oxidative stress is the most important causative factor underlying the onset of several skin problems ${ }^{10-12)}$. Oxidative stress accelerates the progression of skin aging, which is characterized by deep wrinkles, laxity and pigmented spots such as solar lentigos ${ }^{13)}$. Thus, to prevent or improve skin problems initiated by oxidative stress, the reinforcement of the antioxidation capability in the skin is a smart strategy. Two approaches to reinforce

\footnotetext{
*Correspondence to: Hitoshi Masaki, Tokyo University of Technology, 1404-1 Katakura-machi, Hachioji-shi, 192-0982 Tokyo, JAPAN E-mail: masaki@stf.teu.ac.jp Accepted March 4, 2020 (received for review November 6, 2019) Journal of Oleo Science ISSN 1345-8957 print / ISSN 1347-3352 online http://www.jstage.jst.go.jp/browse/jos/ http://mc.manusriptcentral.com/jjocs
} 
the antioxidation capability of the skin are feasible: one is the topical application of antioxidants such as $L$-ascorbic acid, $D L$ - $\alpha$-tocopherol and polyphenols ${ }^{14)}$, while the other is to enhance the capability of intracellular antioxidants by stimulating the corresponding signals ${ }^{15)}$.

On the other hand, there has been recent increased interest in the intake of natural oils for health, because it has been shown that a Mediterranean diet with vegetables and olive oils reduces the risk of cancer and arteriosclerosis ${ }^{16)}$. Therefore, the production of olive oils is increasing gradually even in Japan. As a result, residues after the extraction of olive oils are increasing as industrial wastes year by year. Olive oils contain several antioxidants such as o-diphenols, oleuropein and hydroxytyrosol ${ }^{17,18)}$. It has been demonstrated that the effects of olive oils on health are due to responsible for their antioxidation property ${ }^{19,20}$. These facts suggest that some antioxidants or substances that can effectively reinforce the intracellular antioxidation capability still remain in the residues of olive fruit (ROF) after the extraction of oils. Olive fruits at different stages of maturation are the commonly used sources of olive oils.

Thus, in this study we sought to determine whether the ROF after oil extraction could be utilized, focusing on antioxidation from the chemical and biological aspects and we also investigated differences in the efficacy of the ROF depending on the maturation stages, young and mature.

\section{Experimental Procedures}

\subsection{Materials}

The ROF after oil extraction was a kind gift from the Ao no diamond. Co. Ltd. (Kagawa, Japan). $\mathrm{H}_{2} \mathrm{O}_{2}, L$-ascorbic acid, $D L-\alpha$ tocopherol and xanthine oxidase were purchased from Nacalai tesque (Kyoto, Japan). Iron(II) perchlorate $\left(\mathrm{Fe}\left(\mathrm{ClO}_{4}\right)_{2}\right), 4$-amino antipyrine and hypoxanthine (HPX) were purchased from FUJIFILM Wako Pure Chemical Corporation (Osaka, Japan). 5,5-Dimethyl-1-pyrroline $\mathrm{N}$-oxide (DMPO), tert-butyl hydroperoxide ( $t$-BuOOH), phenol, and diethylenetriamine- $\mathrm{N}, \mathrm{N}, \mathrm{N}^{\prime}, \mathrm{N}^{\prime}$-pentaacetic acid (DTPA) were purchased from Tokyo Chemical Industry (Tokyo, Japan). 5,5'Dithiobis (2-nitrobenzoic acid; DTNB) were purchased from Dojindo Laboratories (Kumamoto, Japan). Peroxidase and ReverTra Ace qPCR Master Mix were obtained from Toyobo (Osaka, Japan). Triton X-100 reduced and Bovine Serum Albumin(BSA)were obtained from Sigma-Aldrich (Missouri, USA). $\mathrm{H}_{2}$ DCFDA was obtained from Merck (Darmstadt, Germany). BCA protein assay kit and DyLight 488 conjugated Streptavidin were obtained from Thermo Fisher Scientific (Massachusetts, USA). The rabbit anti-Nrf2 (Nuclear factor erythroid 2-related factor 2) polyclonal antibody and biotin-conjugated goat anti-rabbit IgG (H\&L) were purchased from Abcam (Cambridge, UK). Hoechst 33342 and HRP-conjugated goat anti-rabbit IgG $(\mathrm{H}+\mathrm{L})$ secondary antibody were obtained from Invitrogen Corporation (California, USA). $\beta$-NADPH and glutathione reductase were obtained from Oriental Yeast(Tokyo, Japan). Nrf2-small interfering RNA and a random sequence siRNA were obtained from Santa Cruz Biotechnology (Texas, USA). The RNeasy Mini kit was obtained from Qiagen (Valencia, CA).

\subsection{Preparation of the extracts from ROF}

In general, the maturation of olive fruit is classified as 8 stages (from 0 to 7 ) with the skin color. In the study, residues of the extraction oils from young fruits and from mature fruits which were harvested at stage 0 and at stages 6 to 7 respectively, were used for preparation of extracts using following procedure ${ }^{21}$. The extracts from ROF harvested at different times were prepared as the young fruit extract(YE) and the mature fruit extract(ME) as follows: After crushing with an EG-45 grinder (Kalita, Yokohama, Japan), $22.5 \mathrm{~g}$ ROF were immersed in $450 \mathrm{~mL} 50 \%$ ethanol aqueous solution for a week at room temperature. The extract was then separated into the extract solution and the ROF by filtration. The extract was then dried with a NAJ-160 rotary evaporator (Tokyo Rikakikai, Tokyo, Japan) and the dried powder was dissolved in a $50 \%$ ethanol aqueous solution at $100 \mathrm{mg} / \mathrm{mL}$ as a stock solution. To use for experiments, the stock solution was diluted with culture medium.

\subsection{Cell culture}

HaCaT keratinocytes were cultured in Dulbecco's modified Eagle medium(DMEM) (Nissui, Tokyo, Japan) supplemented with $5 \%$ fetal bovine serum (FBS) (Biowest, Nuaillé, France) and incubated in a humidified atmosphere of $95 \%$ air and $5 \% \mathrm{CO}_{2}$ at $37^{\circ} \mathrm{C}$.

\subsection{Biological scavenging capabilities of the YE and the ME against extracellular $\mathrm{H}_{2} \mathrm{O}_{2}$}

HaCaT keratinocytes were seeded at a density of $3.5 \times$ $10^{4}$ cells/well in 96 well plates and were cultured in DMEM containing $5 \%$ FBS in the presence or absence of the YE or the ME for $24 \mathrm{~h}$. After loading with $20 \mu \mathrm{M} \mathrm{H}_{2} \mathrm{DCDFA}$ for $30 \mathrm{~min}$, HaCaT keratinocytes were exposed to $500 \mu \mathrm{M} \mathrm{H}_{2} \mathrm{O}_{2}$ for $15 \mathrm{~min}$. The fluorescence intensity(F.I.) (Ex; $485 \mathrm{~nm}$, Em; $530 \mathrm{~nm}$ ) derived from $\mathrm{H}_{2}$ DCDFA oxidized by the remaining $\mathrm{H}_{2} \mathrm{O}_{2}$ was measured. After lysing with $0.5 \%$ Triton$\mathrm{X}$ in PBS, proteins in the lysates were quantified with the BCA protein assay kit. Intracellular ROS levels are ex-

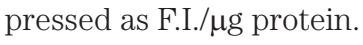

\subsection{Suppressive effects of the YE on intracellular ROS and carbonylated proteins $(\mathrm{CP})$ induced by cortisol}

HaCaT keratinocytes were seeded at a density of $3.5 \times$ $10^{4}$ in 96 well plates and were cultured in DMEM containing $5 \% \mathrm{FBS}$ in the presence of YE for $24 \mathrm{~h}$. After loading 
with $20 \mu \mathrm{M} \mathrm{H} \mathrm{H}_{2} \mathrm{DCDFA}$ for $30 \mathrm{~min}$, HaCaT keratinocytes were cultured with $200 \mu \mathrm{M}$ cortisol for $24 \mathrm{~h}$. Intracellular ROS levels were measured using the procedure described in section 2.4. Intracellular CP levels were quantified by analysing fluorescence images obtained with a Floid Cell Imaging Station (Life Technologies, Carlsbad, CA, USA) after labeling with $20 \mu \mathrm{M}$ FTSC in $0.1 \mathrm{M}$ MES-Na buffer $(\mathrm{pH}$ 5.5) for $1 \mathrm{~h}$ and staining nuclei with $2 \mu \mathrm{M}$ Hoechst 33342. The image analysis was carried out with Corneocytometry software(CIEL, Tokyo, Japan).

\subsection{Chemical scavenging capabilities of the $Y E$ and the $\mathrm{ME}$ against superoxide anion radicals $\left(\cdot \mathrm{O}_{2}^{-}\right), \mathrm{H}_{2} \mathrm{O}_{2}$, hydroxyl radicals $(\cdot \mathrm{OH})$ and lipid peroxyl radicals (LOO.)}

Scavenging against $\mathrm{H}_{2} \mathrm{O}_{2}$ was examined by quantification of the $\mathrm{H}_{2} \mathrm{O}_{2}$ remaining after incubation with $\mathrm{H}_{2} \mathrm{O}_{2}$ and $\mathrm{YE}$ or $\mathrm{ME}$ at various concentrations. Quantification of $\mathrm{H}_{2} \mathrm{O}_{2}$ levels was carried out by measuring the absorbance at $550 \mathrm{~nm}$ of a mixture that was reacted with $\mathrm{H}_{2} \mathrm{O}_{2}$ and 4-amino antipyrine $(0.8 \mathrm{mM})$, phenol $(4 \mathrm{mM})$ in the presence of peroxidase $(725 \mu \mathrm{g} / \mathrm{mL})$ at $37^{\circ} \mathrm{C}$ for $30 \mathrm{~min}$. Scavenging against $\cdot \mathrm{O}_{2}{ }^{-}$, $\cdot \mathrm{OH}$ and $\mathrm{LOO} \cdot$ were measured by the ESR spin-trapping method $^{22-24)}$ using a RFR-30 spectrometer (Radical Research, Tokyo, Japan). Scavenging against $\cdot \mathrm{O}_{2}{ }^{-}$was measured by mixing XOD $(0.19 \mathrm{U} / \mathrm{mL})$ with an aqueous solution containing HPX (0.45 mM), DTPA (1.14 mM), DMPO (90 $\mathrm{mM}$ ) and $\mathrm{YE}$ or $\mathrm{ME}$ at various concentrations. Scavenging against $\cdot \mathrm{OH}$ was measured by mixing $\mathrm{H}_{2} \mathrm{O}_{2}(0.11 \mathrm{mM})$ with an aqueous solution containing $\mathrm{Fe}\left(\mathrm{ClO}_{4}\right)_{2}(0.02 \mathrm{mM})$, $\mathrm{DMPO}(90 \mathrm{mM})$ and $\mathrm{YE}$ or ME at various concentrations. Scavenging against LOO - was measured by mixing $t$-BuOOH $(1.9 \mathrm{mM})$ with an aqueous solution containing $\mathrm{Fe}$ $\left(\mathrm{ClO}_{4}\right)_{2}(0.12 \mathrm{mM}), \mathrm{DTPA}(1.18 \mathrm{mM}), \mathrm{DMPO}(90 \mathrm{mM})$ and YE or ME at various concentrations. After mixing for $1 \mathrm{~min}$, ESR spectra were measured using the following conditions; output power: $4.0 \mathrm{~mW}$, scanning field: $336.5 \pm 7.5 \mathrm{mT}$, modulation frequency: $0.25 \mathrm{mT}$, response time: $0.03 \mathrm{~s} . \mathrm{Mn}^{2+}$ doped in $\mathrm{MnO}$ was used as an external standard. Each radical intensity was calculated as the value which was the normalized height of the radical derived signal with the height of the $\mathrm{Mn}^{2+}$ derived signal. The scavenging capability against each radical was expressed as $\mathrm{IC}_{50}, 50 \%$ scavenging concentration. In addition, the scavenging capability of each type of ROS is estimated compared with the $\mathrm{IC}_{50}$ value of a typical scavenger, $L$-ascorbic acid for $\cdot \mathrm{O}_{2}{ }^{-}, \mathrm{H}_{2} \mathrm{O}_{2}$ and $\cdot \mathrm{OH}$ and $D L$ - $\alpha$-tocopherol for LOO .

\subsection{Activation of Nrf2 signaling}

2.7.1 Translocation of Nrf2 into nuclei

HaCaT keratinocytes cultured with YE for $5 \mathrm{~h}$ were fixed in $4 \%$ formaldehyde for $10 \mathrm{~min}$ at room temperature. After blocking with $1 \%$ BSA for $1 \mathrm{~h}$, cells were incubated with an anti-Nrf2 polyclonal antibody $(2 \mu \mathrm{g} / \mathrm{mL})$ at $4^{\circ} \mathrm{C}$ overnight.
After washing with $0.05 \%$ PBST, cells were incubated with goat anti-rabbit IgG conjugated biotin $(0.5 \mathrm{ng} / \mathrm{mL})$ at room temperature, and then were further incubated with DyLight 488 conjugated streptavidin $(1 \mathrm{mg} / \mathrm{mL})$ for $1 \mathrm{~h}$ in the dark at room temperature. After staining of nuclei with $4 \mu \mathrm{M}$ Hoechst 33342, the translocation of Nrf2 was observed using a BZ-X810 fluorescence microscope(Keyence, Osaka, Japan).

2.7.2 Expression of $\gamma$-glutamyl cysteine synthetase $(\gamma$-GCS) mRNA assessed by real time-PCR

Total RNAs of HaCaT keratinocytes cultured with or without the YE for $6 \mathrm{~h}$ were extracted using a RNeasy Mini kit according to the manufacturer's protocol and were used for single-stranded cDNA synthesis by ReverTra Ace qPCR RT Master Mix. Quantitative real-time PCR (qPCR) was performed using the SYBR Green Gene Expression Assay with an Eco Real-Time PCR System. The following primer sets for $\gamma$-GCS and glyceraldehyde 3-phosphate dehydrogenase (GAPDH) were used: $\gamma$-GCS forward 5'-TTGCAGGAAGGCATTGATCA-3', $\gamma$-GCS reverse 5'-GCATCATCCAGGTGTATTTTCTCTT-3', GAPDH forward 5' TGCACCACCAACTGCTTAGC-3', GAPDH reverse 5'GGCATGGACTGTGGTCATGAG-3'. Data analysis was based on the $\Delta \Delta \mathrm{Ct}$ method with normalization of the housekeeping gene, GAPDH.

2.7.3 Quantification of glutathione (GSH) levels in HaCaT keratinocytes with the knock-down of Nrf2

HaCaT keratinocytes $\left(3.5 \times 10^{4}\right.$ cells/well $)$ were cultured with Nrf2-small interfering RNA (siNrf2) or with a random sequence siRNA as a control (siNC) at a concentration of $100 \mathrm{nM}$ using Lipofectamine RNAiMAX for $48 \mathrm{~h}$. Nrf2 mRNA levels in HaCaT keratinocytes were then measured using the Real-Time PCR system. Amounts of total GSH in lysates of HaCaT keratinocytes were quantified by the GSH reductase recycling assay ${ }^{25)}$. GSH is expressed as pmol GSH normalized with proteins in the lysates determined using the $\mathrm{BCA}$ protein assay kit.

\subsection{Statistics}

All data are expressed as means \pm S.D. Comparisons between two groups were performed using Student's t test. A $p$-value of $<0.05$ is considered statistically significant.

\section{Results}

\subsection{Biological and chemical characteristics of the YE and the ME to scavenge ROS}

In order to identify the antioxidant characteristics of the $\mathrm{YE}$ and the $\mathrm{ME}$, the reducing properties of those extracts against ROS were examined from biological and chemical aspects. HaCaT keratinocytes that were pretreated with the $\mathrm{YE}$ or the ME for $24 \mathrm{~h}$ not only showed reductions of intracellular $\mathrm{H}_{2} \mathrm{O}_{2}$ elevated by extracellular exposure to 

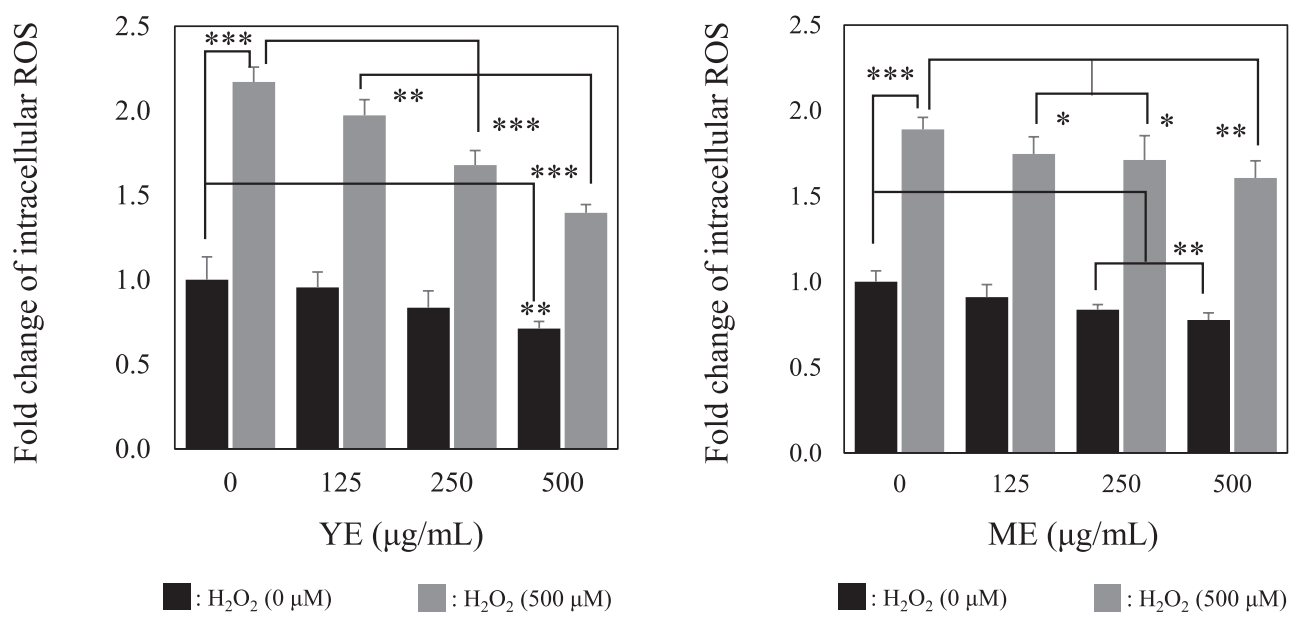

Fig. 1 Biological scavenging of the $\mathrm{YE}$ and the $\mathrm{ME}$ against extracellular exposure to $\mathrm{H}_{2} \mathrm{O}_{2}$.

HaCaT keratinocytes were cultured in the presence or absence of the (left) YE or the ME (right) for $24 \mathrm{~h}$. After loading with $20 \mu \mathrm{M} \mathrm{H} \mathrm{H}_{2} \mathrm{DCDFA}$ for $30 \mathrm{~min}$, keratinocytes were exposed to $500 \mu \mathrm{M} \mathrm{H}_{2} \mathrm{O}_{2}$ for $15 \mathrm{~min}$. The fluorescence intensity (F.I.) (Ex; 485 nm, Em; $530 \mathrm{~nm}$ ) derived from $\mathrm{H}_{2}$ DCDFA oxidized by the remaining $\mathrm{H}_{2} \mathrm{O}_{2}$ was then measured. Intracellular ROS levels are expressed as means \pm standard deviations of fold changes against F.I./ $\mu$ g protein of keratinocytes cultured without the sample and $\mathrm{H}_{2} \mathrm{O}_{2}(\mathrm{n}=5)$. Significance; * $p<0.05, * * p<0.01, * * * p<0.001$.

Table 1 Scavenging capabilities of the YE and the ME against ROS from a chemical aspect.

\begin{tabular}{|c|c|c|c|c|c|c|c|c|c|c|c|c|}
\hline & \multicolumn{12}{|c|}{$\mathrm{IC}_{50}$} \\
\hline & \multicolumn{3}{|c|}{$\cdot \mathrm{O}_{2}^{-}(\mu \mathrm{g} / \mathrm{mL})$} & \multicolumn{3}{|c|}{$\mathrm{H}_{2} \mathrm{O}_{2}(\mathrm{mg} / \mathrm{mL})$} & \multicolumn{3}{|c|}{$\cdot \mathrm{OH}(\mu \mathrm{g} / \mathrm{mL})$} & \multicolumn{3}{|c|}{$\mathrm{LOO} \cdot(\mu \mathrm{g} / \mathrm{mL})$} \\
\hline & Mean \pm S.D. & $\mathrm{p}^{1}$ & $\mathrm{p}^{2}$ & Mean \pm S.D. & $\mathrm{p}^{1}$ & $\mathrm{p}^{2}$ & Mean \pm S.D. & $\mathrm{p}^{1}$ & $\mathrm{p}^{2}$ & Mean \pm S.D. & $\mathrm{p}^{1}$ & $\mathrm{p}^{2}$ \\
\hline Positive control & $27.6 \pm 1.61$ & & & $0.4 \pm 0.1$ & & & $9.6 \pm 0.2$ & & & $13.2 \pm 2.2$ & & \\
\hline YE & $182.1 \pm 31.1$ & $* * *$ & & $3.9 \pm 0.2$ & $* * *$ & & $411.9 \pm 24.9$ & $* * *$ & & $14.3 \pm 0.9$ & N.S. & \\
\hline ME & $196.0 \pm 35.9$ & $* * *$ & N.S. & $8.6 \pm 0.4$ & $* * *$ & $* * *$ & $471.5 \pm 29.6$ & $* * *$ & N.S. & $14.9 \pm 1.2$ & N.S. & N.S. \\
\hline
\end{tabular}

Positive controls: $L$-ascorbic acid was used for $\cdot \mathrm{O}_{2}^{-}, \mathrm{H}_{2} \mathrm{O}_{2}$ and $\cdot \mathrm{OH}$ and $D L$ - $\alpha$-tocopherol was used for LOO $\cdot$ Significance $\mathrm{p}^{1}$; between the positive control and $\mathrm{YE}$ or ME, $\mathrm{p}^{2}$ between $\mathrm{YE}$ and ME, ${ }^{* * *} p<0.001$, N.S. not significant.

$\mathrm{H}_{2} \mathrm{O}_{2}$, but also had reduced levels of intracellular ROS in a steady state (Fig. 1a, b). Meanwhile, the $\mathrm{IC}_{50}$ values of the $\mathrm{YE}$ and the $\mathrm{ME}$ to scavenge $\cdot \mathrm{O}_{2}{ }^{-}, \mathrm{H}_{2} \mathrm{O}_{2}$ and $\cdot \mathrm{OH}$ were significantly higher compared to the positive control except for the scavenging of LOO • (Table 1). Those results suggested that the chemical antioxidative capabilities of the YE and the ME were not high compared with common antioxidants. When considering these results, we speculated that the chemical antioxidative capabilities of the YE and the $\mathrm{ME}$ were not responsible for the reduction of intracellular $\mathrm{H}_{2} \mathrm{O}_{2}$ but rather suggested that the YE and the ME reinforced the intracellular antioxidation capability. In addition, the reduction rate of intracellular $\mathrm{H}_{2} \mathrm{O}_{2}$ showed that the YE was superior to the ME. Thus, in subsequent studies, we examined the antioxidation characteristics of the extracts of ROF focusing on the YE.

\subsection{Effects of the YE on the level of intracellular ROS stimulated by cortisol}

It has been reported that cortisol, a stress hormone, causes oxidative stress through the induction of ROS gen- eration intracellularly. Thus, the effects of the YE against ROS generated intracellularly by stimulation with cortisol were examined. HaCaT keratinocytes precultured with YE for $24 \mathrm{~h}$ showed a significant reduction of intracellular ROS and CPs that were elevated by exposure to cortisol(Fig. 2) . These results indicated that the YE reduced oxidative stress initiated by ROS generated intracellularly.

\subsection{Activation of Nrf2 signaling}

In order to clarify the underlying mechanism of the YE to reduce intracellular oxidative stress, we examined the involvement of Nrf2 signaling focusing on glutathione (GSH) status. HaCaT keratinocytes precultured with the YE showed a translocation of Nrf2 from the cytosol into the nucleus and the upregulation of $\gamma$-GCS mRNA levels (Fig. 3a, b). In addition, although the GSH level in HaCaT keratinocytes was increased by the YE in a dose-dependent manner, that increase was abolished by the knock-down of Nrf2 mRNA levels with a siRNA (Fig. 3c). 
a)



b)

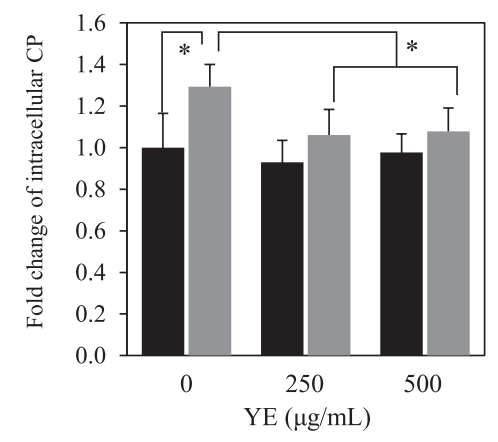

c)

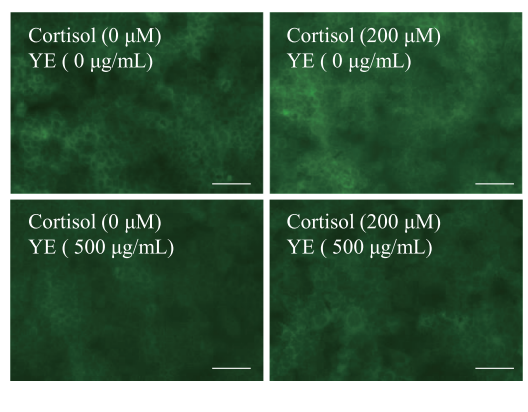

Fig. 2 Reduction capability of the YE against intracellular ROS and CPs elevated by cortisol.

HaCaT keratinocytes were cultured in the presence or absence of the YE for $24 \mathrm{~h}$. a) After loading with $20 \mu \mathrm{M}$ $\mathrm{H}_{2}$ DCDFA for $30 \mathrm{~min}$, keratinocytes were cultured with or without $200 \mu \mathrm{M}$ cortisol for $24 \mathrm{~h}$. Intracellular ROS levels are expressed as means \pm standard deviations of fold changes against F.I./ $\mu$ g protein of cells cultured without the YE and cortisol $(n=5)$. b) Intracellular CPs were quantified by the analysis of images fluorescence-labeled with FTSC, and are expressed as means \pm standard deviations of fold changes against the green fluorescence derived from $\mathrm{CP}$ in keratinocytes cultured without the YE and $\operatorname{cortisol}(n=5)$. c) Representative images of cells cultured without or with the YE and cortisol. Scale bars: $100 \mu \mathrm{m}$. Significance; * $p<0.05$.

a)
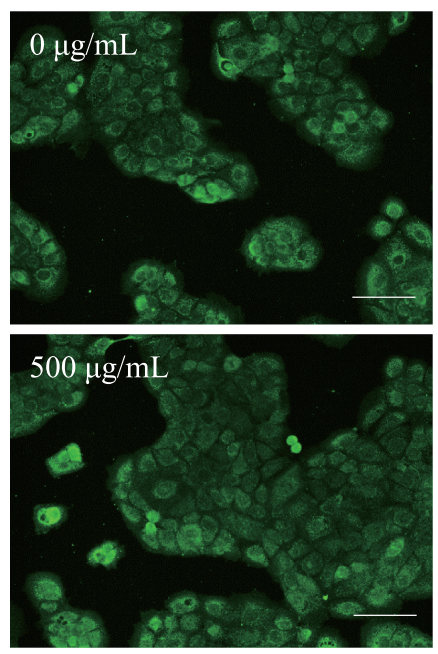

b)

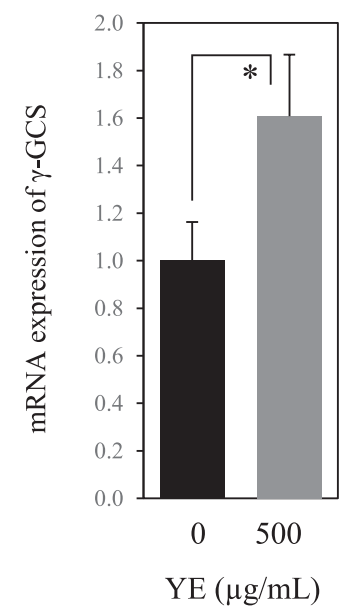

c)

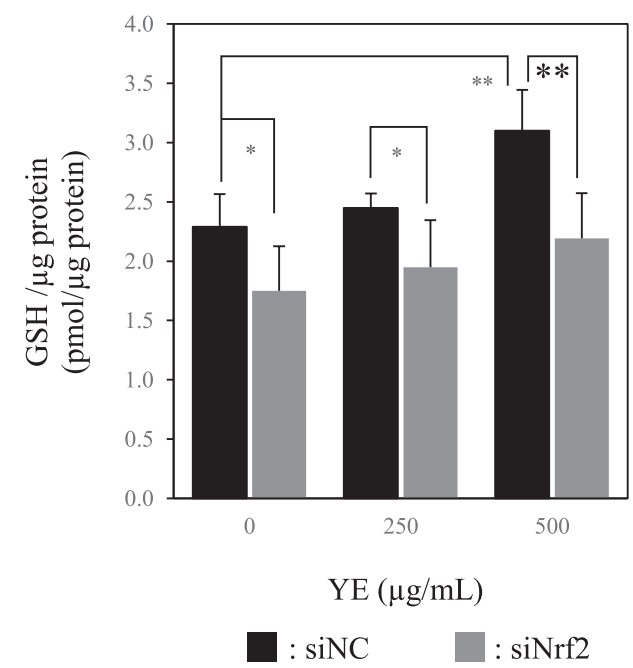

Fig. 3 Activation of Nrf2 signaling by the YE.

a) Representative images of Nrf2 translocation into nuclei. HaCaT keratinocytes were cultured with or without the YE for 5 h. After fixation with 4\% formaldehyde, cells were immunostained with an anti-Nrf2 polyclonal antibody, then with goat anti-rabbit IgG conjugated biotin and DyLight 488 conjugated streptavidin. After staining of nuclei with $4 \mu \mathrm{M}$ Hoechst 33342, the translocation of Nrf2 was observed with a BZ-X810 fluorescence microscope. Scale bars: $100 \mu \mathrm{m}$. b) mRNA expression levels of $\gamma$-GCS in HaCaT keratinocytes cultured with or without the YE for $6 \mathrm{~h}$ quantified by real time-PCR. mRNA expression levels are expressed as means $\pm \operatorname{standard}$ deviations $(\mathrm{n}=3)$. Significance; $* p<0.05$. c) Total glutathione (GSH) levels of HaCaT keratinocytes treated with or without the knockdown by Nrf2 siRNA. HaCaT keratinocytes were cultured with the siNrf2 or a random sequence siRNA (siNC) using Lipofectamine. Amounts of total GSH in lysates of HaCaT keratinocytes cultured with or without the YE for $24 \mathrm{~h}$ were quantified by the GSH reductase recycling assay. GSH levels are expressed as means \pm standard deviations $(\mathrm{n}=$ 6) of pmol GSH normalized to protein levels. Significance; ${ }^{*} p<0.05$, ** $p<0.01$. 


\section{Yoshikawa, T. Mizutani, Y. Okano et al.}

\section{Discussion}

It has been well recognized that exposure to various types of environmental stress, such as sunlight, air pollutants and even mental stress, subjects our bodies to oxidative stress due to the excess generation of $\operatorname{ROS}^{26-28)}$. ROS, which is considered as one of the primary causes that initiates or promotes aging, also introduces acute skin problems such as barrier disruption according to inflammation $^{29)}$. Therefore, to maintain healthy skin conditions, overcoming or eliminating the adverse actions of ROS is an important strategy. As effective solutions, two approaches are considered: one is the systemic or topical uptake of antioxidants and the other is to reinforce the endogenous antioxidant capacity. Each of those approaches has advantages and drawbacks. In general, it is difficult to keep the antioxidative capability in antioxidant products due to their high reactivity with oxygen, although they do show rapid effects. On the other hand, although the reinforcement of antioxidation capability in the body or in cells requires a long period until the effects are evident, the substances that reinforce them are stable in products and it is also possible to deliver them to the target organs or systemically.

On the other hand, the recent trend for seeking health is the increased consumption of olive oils, and results in increased amounts of ROF after the extraction of oils as industrial wastes. Since olive oils contain some antioxidants such as $O$-diphenols, oleuropein and hydroxytyrosol ${ }^{17,18)}$, it was expected that extracts of ROF after extracting oils have the potential to show antioxidant characteristics. Thus, this study was conducted to utilize ROF as a source of antioxidants, and the results would be presumed to reduce the amount of industrial wastes.

In our initial experiments, we found that the YE and the ME had biological antioxidant capabilities despite their relatively low chemical antioxidant capability (Fig. 1, Table 1). In addition, the biological action of the YE was superior compared to the ME. Thus, we investigated the antioxidative characteristics of the extract of ROF focusing on the $\mathrm{YE}$.

A previous study demonstrated that excess intracellular ROS is responsible for dysfunction of the epidermal barrier ${ }^{10)}$. On the other hand, as human beings, we are always exposed to the risk of suffering from psychological stress due to vigorous social changes. Indeed, some studies have reported that hormones released by responses to psychological stress increase the risk of diseases such as hypertension, immune dysfunction and cancer ${ }^{30,31)}$. It has been reported that cortisol also disrupts epidermal barrier function $^{32)}$. Thus, to reduce excess intracellular ROS elevated by various stimuli is important to maintain healthy skin conditions. In this study, cortisol, which is a psychological stress hormone, was used to elevate intracellular ROS, and the reducing effect of the YE on the ROS eleva- tion induced by cortisol was evaluated. In that study, intracellular ROS and CPs were adopted as parameters for evaluation. CPs are end-products of oxidative stress, because they are synthesized by reactions between amino residues in proteins and aldehyde compounds yielded during lipid peroxidation initiated by $\mathrm{ROS}^{33,34)}$. Our recent study found that levels of intracellular CPs correlated with the loss of epidermal barrier function due to the down-regulation of transglutaminase-1, which is an enzyme involved in the formation of the cornified cell envelope due to its crosslinking activity (data not shown). The fact suggested the importance of eliminating ROS and CPs in order to maintain epidermal barrier function. HaCaT keratinocytes cultured with cortisol after $24 \mathrm{~h}$ pretreatment with the YE showed a lower frequency both in intracellular ROS and in CPs compared with sham-treated cells (Fig. 2). Those results indicated that the YE reduced the intracellular ROS elevation stimulated by cortisol, and suggested the possibility of ameliorating adverse actions initiated by psychological stress. In addition, those results suggested that the YE enhanced the intracellular antioxidant capability, because the reduction of intracellular ROS was observed even in the absence of cortisol.

In general, the intracellular antioxidation capability is regulated by the Nrf2-antioxidant response element (ARE) pathway ${ }^{35)}$. Nrf2, which binds to ARE after translocation into the nuclear region, regulates the ARE-mediated expression of genes such as $\gamma$-GCS and heme oxygenase- $1^{15,36)}$. Thus, we investigated the effects of the YE on Nrf2 signaling focusing on the GSH status. YE enhanced the translocation of Nrf2 into nuclei from the cytosol and upregulated mRNA levels of $\gamma$-GCS, which is the rate-limiting enzyme of GSH synthesis (Fig. 3a, b). Indeed, the YE also increased the level of intracellular total GSH(Fig. 3c). Furthermore, knock-down of Nrf2 mRNA expression using a siRNA abolished the increases of GSH(Fig. 3c). The sum of these results indicates that the YE reinforces the intracellular antioxidation capability through Nrf2 signaling. At this time, we don't have any results suggesting the active substance (s) in the YE. However, it has been reported that some phytochemicals like polyphenols also work as stimulators of Nrf2 signaling. Thus, we will continue this study to identify the bioactive substances in the YE that stimulates Nrf2 signaling, and will report that elsewhere.

\section{Conclusion}

In summary, these results indicate that an extract of young ROF after the extraction of oils has the ability to reinforce the intracellular antioxidation capability through Nrf2 signaling and support its potential use to maintain healthy skin. Furthermore, since utilizing the ROF leads to the reduction of industrial wastes, the results of this study 
are a social contribution to improve the environment of the earth.

\section{References}

1) Kruk, J.; Duchnik, E. Oxidative stress and skin diseases: possible role of physical activity. Asian Pac. J. Cancer Prev. 15, 561-568(2014).

2) Beak, S.M.; Lee, Y.S.; Kim, J.A. NADPH oxidase and cyclooxygenase mediate the ultraviolet B-induced generation of reactive oxygen species and activation of nuclear factor-kappaB in HaCaT human keratinocytes. Biochimie 86, 425-429 (2004).

3) Valencia, A.; Kochevar, I.E. Nox1-based NADPH oxidase is the major source of UVA-induced reactive oxygen species in human keratinocytes. J. Invest. Dermatol. 128, 214-222(2008).

4) Mizutani, T.; Sumida, H.; Sagawa, Y.; Okano, Y.; Masaki, H. Carbonylated proteins exposed to UVA and to blue light generate reactive oxygen species through a type I photosensitizing reaction. J. Dermatol. Sci. 84, 314321 (2016).

5) Andersson, H.; Piras, E.; Demma, J.; Hellman, B.; Brittebo, E. Low levels of the air pollutant 1-nitropyrene induce DNA damage, increased levels of reactive oxygen species and endoplasmic reticulum stress in human endothelial cells. Toxicology 262, 57-64(2009).

6) Ferecatu, I.; Borot, M.C.; Bossard, C.; Leroux, M.; Boggetto, N.; Marano, F.; Baeza-Squiban, A.; Andreau, K. Polycyclic aromatic hydrocarbon components contribute to the mitochondria-antiapoptotic effect of fine particulate matter on human bronchial epithelial cells via the aryl hydrocarbon receptor. Part. Fibre Toxicol. 7, 18(2010).

7) Puri, P.; Nandar, S.K.; Kathuria, S.; Ramesh, V. Effects of air pollution on the skin: A review. Indian J. Dermatol. Venereol. 83, 415-423(2017).

8) Zhang, H.; Yao, Z.; Lin, L.; Sun, X.; Shi, X.; Zhang, L. Early life stress predicts cortisol response to psychosocial stress in healthy young adults. PsyCh J. 8, 353362 (2019).

9) Espinoza, M.B.; Aedo, J.E.; Zuloaga, R.; Valenzuela, C.; Molina, A.; Valdes, J.A. Cortisol induces reactive oxygen species through a membrane glucocorticoid receptor in rainbow trout myotubes. J. Cell. Biochem. 118, 718-725(2017).

10) Ji, H.; Li, X.K. Oxidative stress in atopic dermatitis. Oxid. Med. Cell. Longevity 2016, 2721469 (2016).

11) Song, I.B.; Gu, H.; Han, H.J.; Lee, N.Y.; Cha, J.Y.; Son, Y.K.; Kwon, J. Effects of 7-MEGA(TM) 500 on oxidative stress, inflammation, and skin regeneration in $\mathrm{H}_{2} \mathrm{O}_{2}$-treated skin cells. Toxicol. Res. 34, 103-110 (2018).
12) Tobin, D.J. Introduction to skin aging. J. Tissue Viability 26, 37-46 (2017).

13) Lephart, E.D. Skin aging and oxidative stress: Equol's anti-aging effects via biochemical and molecular mechanisms. Ageing Res. Rev. 31, 36-54(2016).

14) Bohles, H. Antioxidative vitamins in prematurely and maturely born infants. Int. J. Vitam. Nutr. Res. 67, 321-328 (1997).

15) Jaiswal, A.K. Nrf2 signaling in coordinated activation of antioxidant gene expression. Free Radical Biol. Med. 36, 1199-1207 (2004).

16) Willett, W.C.; Sacks, F.; Trichopoulou, A.; Drescher, G.; Ferro-Luzzi, A.; Helsing, E.; Trichopoulos, D. Mediterranean diet pyramid: A cultural model for healthy eating. Am. J. Clin. Nutr. 61, 1402s-1406s (1995).

17) Rojas, D.; Della Pelle, F.; Del Carlo, M.; Fratini, E.; Escarpa, A.; Compagnone, D. Nanohybrid carbon blackmolybdenum disulfide transducers for preconcentration-free voltammetric detection of the olive oil odiphenols hydroxytyrosol and oleuropein. Mikrochim. Acta 186, 363 (2019).

18) Richard, N.; Arnold, S.; Hoeller, U.; Kilpert, C.; Wertz, K.; Schwager, J. Hydroxytyrosol is the major anti-inflammatory compound in aqueous olive extracts and impairs cytokine and chemokine production in macrophages. Planta Med. 77, 1890-1897(2011).

19) Abdallah, M.; Marzocco, S.; Adesso, S.; Zarrouk, M.; Guerfel, M. Olive oil polyphenols extracts inhibit inflammatory markers in J774A.1 murine macrophages and scavenge free radicals. Acta Histochem. 120, 1-10 (2018).

20) Dairi, S.; Carbonneau, M.A.; Galeano-Diaz, T.; Remini, H.; Dahmoune, F.; Aoun, O.; Belbahi, A.; Lauret, C.; Cristol, J.P.; Madani, K. Antioxidant effects of extra virgin olive oil enriched by myrtle phenolic extracts on iron-mediated lipid peroxidation under intestinal conditions model. Food Chem. 237, 297-304(2017).

21) Mínguez-Mosquera, I.; Gallardo-Guerrero, L. Disappearance of chlorophylls and carotenoids during the ripening of the olive. J. Sci. Food Agric. 69, 1-6 (1995).

22) Kitagawa, S.; Fujisawa, H.; Kametani, F. Sakurai, H. Generation of active oxygen species in blood plateletsspin trapping analysis. Free Radical Res. Commun. 15, 319-324 (1992).

23) Nishi, J.; Ogura, R.; Sugiyama, M.; Hidaka, T.; Kohno, M. Involvement of active oxygen in lipid peroxide radical reaction of epidermal homogenate following ultraviolet light exposure. J. Invest. Dermatol. 97, 115-119 (1991).

24) Masaki, H.; Atsumi, T.; Sakurai, H. Hamamelitannin as a new potent activity oxygen scavenger. Phytochemistry 37, 337-343 (1994).

25) Masaki, H.; Okano, Y.; Ochiai, Y.; Obayashi, K.; Aka- 
matsu, H.; Sakurai, H. alpha-Tocopherol increases the intracellular glutathione level in HaCaT keratinocytes. Free Radical Res. 36, 705-709 (2002).

26) Svobodova, A.; Walterova, D.; Vostalova, J. Ultraviolet light induced alteration to the skin. Biomed Pap Med Fac Univ Palacky Olomouc Czech Repub. 150, 25-38 (2006).

27) Oh, Y.; Lim, H.W.; Park, K.H.; Huang, Y.H.; Yoon, J.Y.; Kim, K.; Lim, C.J. Ginsenoside Rc protects against UVBinduced photooxidative damage in epidermal keratinocytes. Mol. Med. Rep. 16, 2907-2914(2017).

28) Flaherty, R.L.; Owen, M.; Fagan-Murphy, A.; Intabli, H.; Healy, D.; Patel, A.; Allen, M.C.; Patel, B.A.; Flint, M.S. Glucocorticoids induce production of reactive oxygen species/reactive nitrogen species and DNA damage through an iNOS mediated pathway in breast cancer. Breast Cancer Res. 19, 35 (2017).

29) Jin, S.P.; Li, Z.; Choi, E.K.; Lee, S.; Kim, Y.K.; Seo, E.Y.; Chung, J.H.; Cho, S. Urban particulate matter in air pollution penetrates into the barrier-disrupted skin and produces ROS-dependent cutaneous inflammatory response in vivo. J. Dermatol. Sci. 91, 175-183 (2018).

30) Liu, M.Y.; Li, N.; Li, W.A.; Khan, H. Association be- tween psychosocial stress and hypertension: a systematic review and meta-analysis. Neurol. Res. 39, 573580 (2017).

31) Cohen, S.; Janicki-Deverts, D.; Miller, G.E. Psychological stress and disease. JAMA 298, 1685-1687 (2007).

32) Choe, S.J.; Kim, D.; Kim, E.J.; Ahn, J.S.; Choi, E.J.; Son, E.D.; Lee, T.R.; Choi, E.H. Psychological stress deteriorates skin barrier function by activating 11betahydroxysteroid dehydrogenase 1 and the HPA axis. Sci. Rep. 8, 6334 (2018).

33) Yamawaki, Y.; Mizutani, T.; Okano, Y.; Masaki, H. The impact of carbonylated proteins on the skin and potential agents to block their effects. Exp. Dermatol. 28 (Suppl. 1), 32-37 (2019).

34) Fedorova, M.; Bollineni, R.C.; Hoffmann, R. Protein carbonylation as a major hallmark of oxidative damage: Update of analytical strategies. Mass Spectrom. Rev. 33, 79-97 (2014).

35) Kaspar, J.W.; Niture, S.K.; Jaiswal, A.K. Nrf2:INrf2 (Keap1) signaling in oxidative stress. Free Radical Biol. Med. 47, 1304-1309 (2009).

36) Homma, T.; Fujii, J. Application of glutathione as antioxidative and anti-aging drugs. Curr. Drug Metab. 16, 560-571 (2015). 